\title{
Physical sorption and thermogravimetry as the methods used to analyze linear polymeric structure
}

\author{
Paweł Mergo • Małgorzata Gil • Wiesław Podkościelny • \\ Marta Worzakowska
}

Received: 31 October 2012/Accepted: 27 February 2013/Published online: 10 March 2013

(C) The Author(s) 2013. This article is published with open access at Springerlink.com

\begin{abstract}
An increased interest in polymer optical fibers can be observed in the last years. One of the main problems in the technology of these fibers is achieving good optical and thermal stability of used polymer materials. This paper presents a series of manufactured poly(methyl methacryalte) samples which quality was investigated using the physical sorption and the thermogravimetry methods. Studies were carried out to optimize the composition of the starting mixtures used to obtain proper polymer optical fibers.
\end{abstract}

Keywords Optical fibers - Thermogravimetry ·

Adsorption · Polymer · Technology

\section{Introduction}

An increased interest in polymer optical fibers can be observed in the last years. This is due to the differences in properties between them and the silica glass optical fibers. Silica optical fibers, for telecommunication applications, have a relatively small diameter, usually $125 \mu \mathrm{m}$, to allow

The work was presented at Eight International Symposium "Effects of Surface Heterogeneity in Adsorption and Catalysis on Solids", 26th-31st August 2012, Krakow, Poland.

P. Mergo $\cdot$ M. Gil $(\bowtie) \cdot$ W. Podkościelny

Laboratory of Optical Fibre Technology, Maria Curie-

Sklodowska University, Lublin, Poland

e-mail: malgorzatagil5@gmail.com

P. Mergo

e-mail: pawel.mergo@umcs.lublin.pl

M. Worzakowska

Department of Polymer Chemistry, Maria Curie-Sklodowska

University, Lublin, Poland them to be flexible despite their inherent brittleness (Griffith 1920). On the other hand the fibers' small diameters cause many problems in terms of coupling and connecting with each other. Polymer optical fibers can be produced with relatively large dimensions, which greatly simplifies coupling. Unfortunately polymer optical fibers have a higher attenuation, due to increased scattering. As opposed to longdistance links, where the attenuation and dispersion effects are critical, short distance networks require more flexibility, easiness of handling, and low-cost connections. Due to their unique features such as low-processing temperatures and great compatibility, which allow for the doping of a wide range of organic materials of special properties, polymer optical fibres (POFs) may acquire special functionalities for various applications in photonics, material science, medicine, optical sensing, optical spectroscopy, etc. (Peng and Chu 1999). Moreover due to a much lower Young's modulus and much higher thermo-optic coefficient of poly(methyl methacryalte) (PMMA) (Large et al. 2009), Bragg gratings written in PMMA POFs have great potential for sensing temperature and strain with higher sensitivities and wider tunability than its silica counterpart (Large et al. 2009; Liu et al. 2001, 2005; Carroll et al. 2007). Fiber bragg grating (FBG) a periodic refractive index modulation within a short length of core section in an optical fiber, works as an array of mirrors which reflects transmission light that satisfies the Bragg condition (Kersey 1996; Du et al. 1998). Furthermore rapid technological progress can substantially reduce the attenuation, even for $25 \mathrm{~dB} \mathrm{~km}^{-1}$ over the wavelength range of 650-1,300 $\mathrm{nm}$ for graded index polymer optical fibers (Im et al. 2002).

In order to obtain a polymer optical fiber with the desired properties, it is necessary to prepare specific preforms from which optical fibers are drawn or extruded. POFs are most commonly made from PMMA, which is 
produced by the polymerization of methyl methacrylate. Pure PMMA is a shiny, amorphous polymer with a very good visible light transmittance of $90-92 \%$. The UV transmittance is approximately $70 \%$, which is much higher than in ordinary glass. However POFs good optical properties can be easily reduced, because of their brittleness. In order to increase the resistance of PMMA to external factors, methyl methacrylate is subjected to copolymerization with other monomers, or covers the surface of the fluorocarbons. PMMA has favorable rheological properties for drawing the fibre from preform. The glass transition temperature for PMMA homopolymer is $105^{\circ} \mathrm{C}$. The drawing can be done at reasonable temperatures of $175-220^{\circ} \mathrm{C}$, depending on the composition. These properties make the direct extrusion process also possible (Dobrosz and Matysiak 1990; Harlin et al. 2002).

Technological problems of polymerization process depend mainly on the optimization of reaction conditions and speed. Special restrictions here are technical issues including the dissipation of heat during the reaction and the viscosity of the product. Studies on the optimization of the method of obtaining preforms were carried out in the Laboratory of Optical Fiber Technology at Maria Curie-Sklodowska University in Lublin for several years. In this paper problems that arise during the course of thermal polymerization process will be attempted to explain using results concerning the mesopores size and the sample mass loss occurring with the increase of temperature.

\section{Experimental}

\subsection{Materials}

Series of preforms, in which the basic component was methyl methacrylate (ALDRICH), were made. Before use, MMA was purified. Very important issues, significantly affecting the properties of the fibers, are the impurities present in the raw materials used in their production. Therefore it is important, that the raw materials were cleaned as much as possible. Impurities (both substrate and undesirable inhibitor, that was added in order to prevent pre-process of autopolymerization of methyl methacrylate) were removed by distillation. The process was carried out under reduced pressure, in which MMA does not change its properties-does not decompose, nor polymerize. The initiator benzoyl peroxide (ALDRICH), which was also purified before its use, and chain transfer agent thioglycolic acid (TGA) (98\% ALDRICH) were used in thermal free radical polymerization of the preforms. Chemical structures of the methyl methacrylate, thioglycolic acid and benzoly peroxide are presented in Fig. 1.

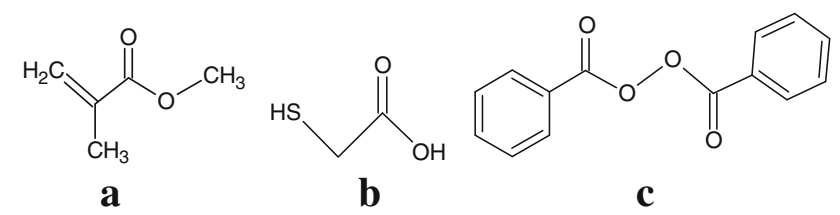

Fig. 1 Chemical structures of the compounds used in thermopolymerization. a Methyl methacrylate, b thioglycolic acid, c benzoyl peroxide

In the fiber optic technology two methods of polymerization are used-thermal and photopolymerization. The course of the reaction, essentially, takes place in the same way, with the main difference being the source of initiation. Due to the crosslinking of the polymer during photopolymerization, this technique is not used in the production of polymeric fiber preforms. The problem of a suitable polymerization process occurs at the very beginning of the polymerization reaction, namely, the appropriate initiator. Commonly used initiators are di-tert-butyl dicarbonate, di-tert-butyl peroxide, azo-bis-izobutyronitryle and benzoyl peroxide, each of which is reactive with a variety of temperature ranges. After selection of a suitable thermal curing process, there is still a problem with the products of the initiation step of the polymerization reaction. Figure 2 presents the thermolysis of the initiator used in our experiment. It can be seen that the product of decomposition of the initiator is a radical initiator and the gas molecule. The same situation, with the emission of various gases concerns the other initiators. Our study analyzes the course of thermal polymerization and possible polymer structure problems resulting from, among others, the presence of gases that arise during the reaction course.

\subsection{Curing procedure}

A series of compositions with MMA as the basic component, benzoyl peroxide (with excitation temperature ranging from 40 to $90{ }^{\circ} \mathrm{C}$ ) as the initiator and thioglycolic acid as the chain transfer agent were prepared (Table 1). After mixing the mentioned ingredients, all of the compositions were prepolymerized, and subsequently the appropriate curing process was applied. The thermal polymerization was carried out in a test tube with an inner diameter of $14 \mathrm{~mm}$. The process was carried out in an oven under vacuum. The temperature was increased gradually from 25 to $110{ }^{\circ} \mathrm{C}$ in 2 days until the solidification was fulfilled. After polymerization all of the tested samples were powdered.

The molecular weights of the resulting polymers were determined by measuring the viscosity of liquids using an Ostwald capillary viscometer, in which the liquid flows through the capillary tube under the influence of the hydrostatic pressure difference between the two arms. 
Fig. 2 Thermolisis of the benzoyl peroxide

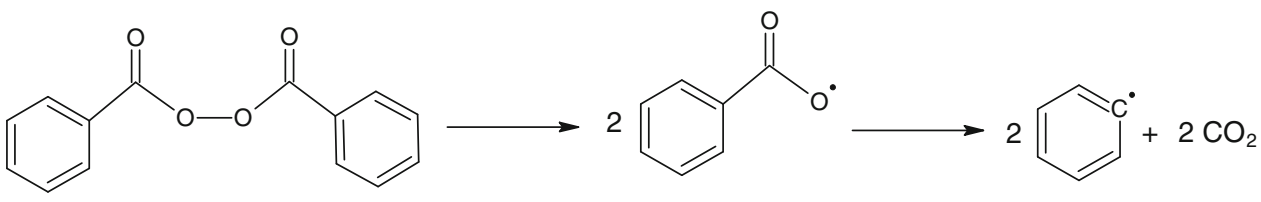

Table 1 Starting composition and molecular weight determined by measuring the viscosity of liquids using Ostwald capillary viscometer

\begin{tabular}{llc}
\hline Sample number & Starting composition (\%) & $\begin{array}{l}\mathrm{Molecular}^{-1} \text { weight } \\
\left(\mathrm{g} \mathrm{mol}^{-1}\right)\end{array}$ \\
\hline 26A & M-0.3\%; I-0.3\% & 786,553 \\
26B & M-0.4\%; I-0.3\% & 225,559 \\
26C & M-0.5\%; I-0.3\% & 48,841 \\
30A & M-0.6\%; I-0.3\% & 53,391 \\
30B & M-0.7\%; I-0.3\% & 39,105 \\
30C & M-0.8\%; I-0.3\% & 19,610 \\
\hline
\end{tabular}

$M$ the chain transfer agent, $I$ initiator

\subsection{Characterization}

Thermal analysis was carried out on a STA 449 Jupiter F1, Netzsch (Selb, Germany) under the following operational conditions: heating rate $10{ }^{\circ} \mathrm{C} \mathrm{min}^{-1}$, a dynamic atmosphere of helium $\left(40 \mathrm{~mL} \mathrm{~min}^{-1}\right)$ in the temperature range of $40-600{ }^{\circ} \mathrm{C}$, sample weight of about $10 \mathrm{mg}$, sensor thermocouple type $\mathrm{S}$ TG-DSC. An empty $\mathrm{Al}_{2} \mathrm{O}_{3}$ crucible was used as a reference.

The identification of a gas composition coming out during the decomposition process was detected and analyzed by a quadrupole mass spectrometer QMS 403C Aëolos (Germany) as well as an FT-IR spectrometer Brucker Tensor 27 TGA 585 (Germany) coupling on-line to the STA instrument. The mass spectrometer was connected on-line to the STA instrument by a quartz capillary heated to $300{ }^{\circ} \mathrm{C}$. The QMS was operated with an electron impact ionizer with energy $70 \mathrm{eV}$. The measurements performed in the scan mode for $\mathrm{m} / \mathrm{z}$, where $m$ is the mass of molecule and $z$ is a charge of the molecule in electron charge units in the range from 10 to $180 \mathrm{amu}$, allowed to identify all possible volatile species produced during the decomposition. The FT-IR spectrometer with an IR cell maintained at $200{ }^{\circ} \mathrm{C}$ was connected on-line to the STA instrument by a transfer line evolved gases from TGA to the FT-IR with diameter of $2 \mathrm{~mm}$ heated to $200{ }^{\circ} \mathrm{C}$. The FT-IR spectra were recorded in the spectral range of $600-4,000 \mathrm{~cm}^{-1}$ with 16 scans per spectrum at a resolution of $4 \mathrm{~cm}^{-1}$.

Characterization of the pore structure of the samples was performed on the basis of low-temperature nitrogen adsorption-desorption isotherms measured on a sorptometer Quantachrome Autosorb iQ. Prior to the adsorption measurements, the samples were degassed in vacuum at
$100{ }^{\circ} \mathrm{C}$ for $2 \mathrm{~h}$. The surface area was calculated with an BET method. Measurement error in the nitrogen adsorption was $5 \%$. The $\mathrm{S}_{\mathrm{BET}}$ (Brunauer et al. 1938) surface area was assessed within the range of relative pressures from 0.05 to 0.3 . The total pore volume $\left(\mathrm{V}_{\mathrm{t}}\right)$ was calculated by measuring the amount of liquid nitrogen adsorbed at a relative pressure $\mathrm{p} / \mathrm{p}_{0}=0.99$. The average pore diameter $(\mathrm{d})$ was calculated from:

$d=\frac{4 \mathrm{~V}_{\mathrm{t}}}{\mathrm{S}_{\mathrm{BET}}}$

\section{Results and discussion}

The addition of moderator limits the growth of the polymer chain. Furthermore the increase of its concentration in the test compositions, causes a decrease in the molecular weight of the obtained polymers. The aim of this study was to determine the effect of the moderator in the thermal polymerization reaction, including the amount and type of gas molecules occluded, its effect on the thermal resistance and the degree of polymerization of the polymers obtained. Based on thermogravimetric studies it was determined at which temperature there is a weight loss, and how quickly it occurs. Tables 2, 3, 4 show the temperature of weight loss determined for each preform.

Based on the data included in Tables 2, 3, 4 and, the analysis of physical and chemical changes were made. First, noticeable by the measuring apparatus, weight loss occurred for all samples around $149-166{ }^{\circ} \mathrm{C}$, but it should be noted that for the sample no. $30 \mathrm{~A}(0.6 \mathrm{w} / \mathrm{w} \%$ moderator) this temperature was $117^{\circ} \mathrm{C}$ and for the sample no. $26 \mathrm{~B}(0.4 \mathrm{w} / \mathrm{w} \%$ moderator $)-166^{\circ} \mathrm{C}$. In the range of $0.01-0.05 \mathrm{w} / \mathrm{w} \%$ weight loss an increase in weight loss, for all tested mixtures, was equally steady and in the range of $1-3 \%$. In the range of $0.1-0.5 \mathrm{w} / \mathrm{w} \%$ weight loss a similar pattern can be observed. For the sample no. 30A already at $130{ }^{\circ} \mathrm{C}$ there was $0.1 \%$ weight loss, while for the sample no.26B the same value of weight loss falls within the temperature of $168{ }^{\circ} \mathrm{C}$. The latter analyzed range of weight loss (Table 4) concerns temperatures at which polymer optical fibers are usually drawn (typically $220{ }^{\circ} \mathrm{C}$ ). Therefore the initial decomposition temperature is the most important temperature in this area, as it determines the temperature at which the fiber drawing process definitively must begin. On this basis, we conclude that the sample (no. 30C) decomposition starts at a high temperature with the lowest loss of weight. However, the sample containing 0.3 
Table 2 Determination of the weight loss temperature from 0.01 to $0.05 \mathrm{w} / \mathrm{w} \%$

\begin{tabular}{llllll}
\hline Sample number $\left({ }^{\circ} \mathrm{C}\right)$ & \multicolumn{6}{l}{ Weight loss $(\mathrm{w} / \mathrm{w} \%)$} \\
\cline { 2 - 6 } & $0.01 \%$ & $0.02 \%$ & $0.03 \%$ & $0.04 \%$ & $0.05 \%$ \\
\hline $26 \mathrm{~A}$ & 154 & 154.5 & 154.5 & 155 & 155.5 \\
$26 \mathrm{~B}$ & 166 & 166.5 & 166.5 & 166.5 & 167 \\
$26 \mathrm{C}$ & 149 & 150 & 150 & 150 & 150.5 \\
30A & 117 & 117.5 & 117 & 118 & 119 \\
$30 \mathrm{~B}$ & 149 & 150 & 150.5 & 151 & 152 \\
$30 \mathrm{C}$ & 149.5 & 150 & 151 & 151 & 152 \\
\hline
\end{tabular}

Table 3 Determination of the weight loss temperature from 0.1 to $0.5 \mathrm{w} / \mathrm{w} \%$

\begin{tabular}{llllll}
\hline Sample number $\left({ }^{\circ} \mathrm{C}\right)$ & \multicolumn{6}{l}{ Weight loss $(\mathrm{w} / \mathrm{w} \%)$} \\
\cline { 2 - 6 } & $0.1 \%$ & $0.2 \%$ & $0.3 \%$ & $0.4 \%$ & $0.5 \%$ \\
\hline $26 \mathrm{~A}$ & 157 & 159.5 & 161 & 162.5 & 164 \\
$26 \mathrm{~B}$ & 168 & 170.5 & 172 & 174 & 175.5 \\
$26 \mathrm{C}$ & 152 & 155.5 & 161 & 165 & 168.5 \\
$30 \mathrm{~A}$ & 130 & 144 & 151 & 156.5 & 160.5 \\
$30 \mathrm{~B}$ & 155 & 160 & 164 & 167.5 & 170.5 \\
$30 \mathrm{C}$ & 156 & 161 & 166 & 170.5 & 174.5 \\
\hline
\end{tabular}

w/w \% moderator starts decomposition at the lowest temperature with high weight loss. For all analyzed mixtures the temperature showing half of the distribution of the sample and the total decomposition, are comparable. Also comparable, for all tested samples, is the amount of energy emitted during proper stage of decomposition, as measured by differential scanning calorimetry.

The issue should be considered in two aspects. First, the higher temperature and less weight loss, the better the sample is cured. Thus, the smaller amount of occluded molecules of volatile substances can be generated under the influence of temperature. The second aspect concerns the situation where the present volatiles and unpolymerized
MMA particles evaporate at the lowest temperature possible, allowing them to get rid of the preform at a temperature lower than the temperature of the polymer optical fiber drawing.

Based on the TG derivative curve, information about the decomposition stages of the tested polymers was obtained. Most of the samples show two-step decomposition. The first stage occurs at temperatures of up to $230{ }^{\circ} \mathrm{C}$, the maximum of this stage falls somewhere about to $180{ }^{\circ} \mathrm{C}$ for each sample. The second stage above $230{ }^{\circ} \mathrm{C}$ is a proper decomposition stage of the sample. Only the sample no. 30C shows the three-step decomposition, which may indicate a heterogeneous polymer structure. It can be presumed that in this case, the separation of the stage of volatiles evaporation (including MMA), evaporation or depolymerization of PMMA and proper samples decomposition take place.

The analysis of the composition and the temperature of functional groups appearance which are the part of the substances were made on the basis of FT-IR spectroscopy (Figs. 3, 4). The spectral range within $1,300-1,050 \mathrm{~cm}^{-1}$ corresponds to the stretching vibrations of $\mathrm{C}-\mathrm{O}$ methyl ester and the rotational vibration of the methyl ester $-\mathrm{CH}_{3}$ (Borowski et al. 2012; Shahzada and Sharif 2007) (Fig. 3). For all samples the increase of the absorption within this range for the two temperature ranges is observed, which corresponds to the decomposition stages read from the TG derivative curve. These ranges are about $140-260{ }^{\circ} \mathrm{C}$, where the maximum occurs at $\sim 200^{\circ} \mathrm{C}$, and the second maximum occurs in the range of $270-520{ }^{\circ} \mathrm{C}$, with an absorption maximum at $390{ }^{\circ} \mathrm{C}$. Only sample no. 30C shows a three-stage emission of these groups $\left(150-230{ }^{\circ} \mathrm{C}\right.$, 230-280 ${ }^{\circ} \mathrm{C}, 280-520^{\circ} \mathrm{C}$ ), the same as it was in the case of thermogravimetric studies, indicating the three stages of decomposition. A similar trend is observed on FT-IR spectra for the stretching vibration of the carbonyl group of the methyl ester which characteristic broad band is within the range $1,800-1,700 \mathrm{~cm}^{-1}$ (Fig. 4). At a wavelength of $1,639 \mathrm{~cm}^{-1}$, the presence of $\mathrm{C}=\mathrm{C}$ groups is probably

Table 4 Determination of the weight loss temperature from 1 to $5 \mathrm{w} / \mathrm{w} \%$, the initial decomposition temperature and the weight loss at this temperature

\begin{tabular}{|c|c|c|c|c|c|c|}
\hline \multirow{2}{*}{$\begin{array}{l}\text { Sample } \\
\text { number }\left({ }^{\circ} \mathrm{C}\right)\end{array}$} & \multicolumn{6}{|c|}{ Weight loss (w/w \%) } \\
\hline & $1 \%$ & $2 \%$ & $3 \%$ & $4 \%$ & $5 \%$ & $\begin{array}{l}\text { Initial decomposition weight } \\
\text { loss/temperature }\end{array}$ \\
\hline $26 \mathrm{~A}$ & 169 & 176 & 182 & 191 & 205 & $6.4 \%-247$ \\
\hline $26 B$ & 182 & 195 & 236 & 288 & 302 & $3.7 \%-264$ \\
\hline $26 \mathrm{C}$ & 186 & 259 & 283 & 298 & 308 & $2.3 \%-242$ \\
\hline $30 \mathrm{~A}$ & 172 & 191 & 285 & 305 & 316 & $2.55 \%-263$ \\
\hline $30 \mathrm{~B}$ & 185 & 252 & 300 & 317 & 326 & $2.5 \%-274$ \\
\hline $30 \mathrm{C}$ & 208 & 286 & 313 & 325 & 333 & $2 \%-270$ \\
\hline
\end{tabular}



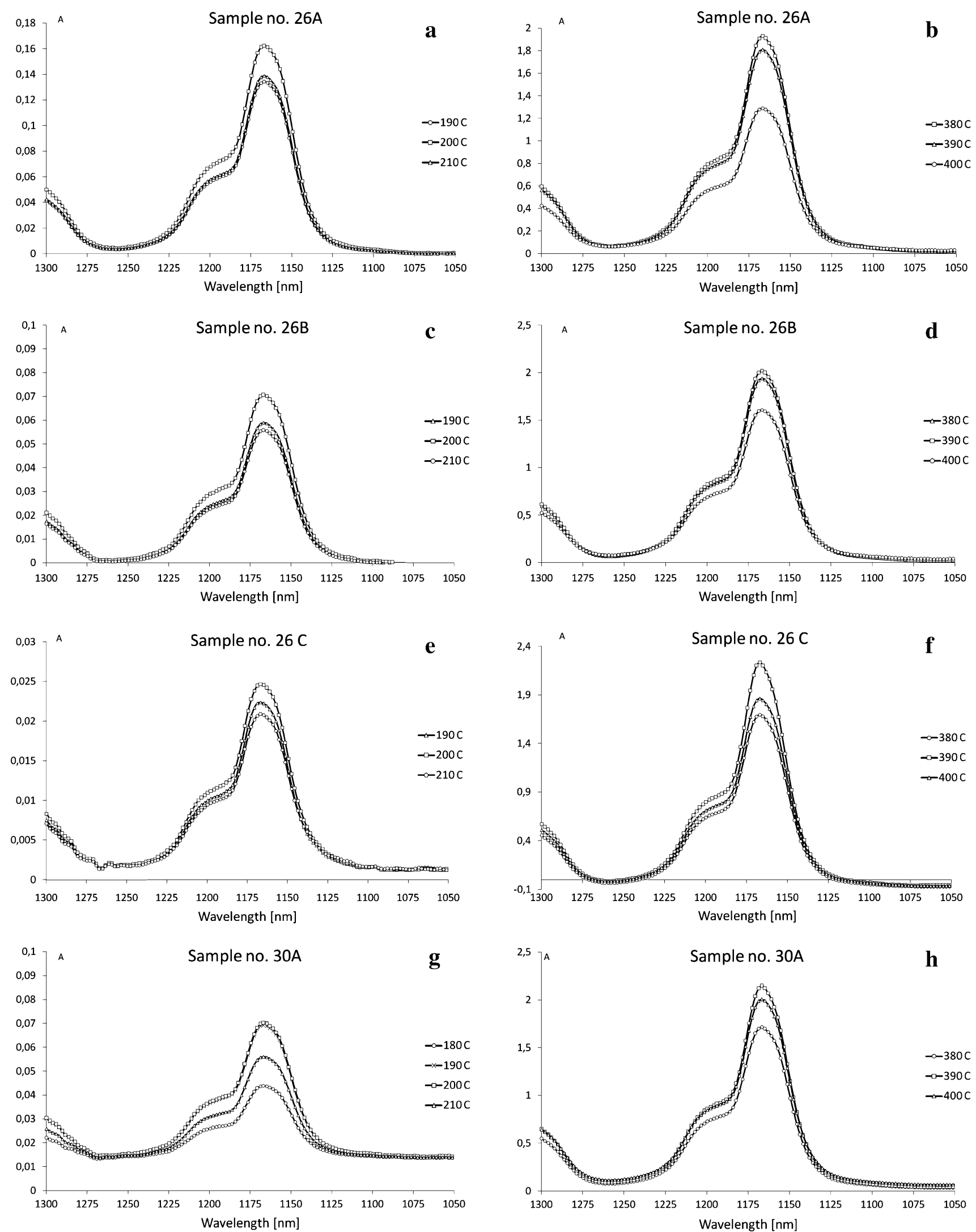

Fig. 3 FT-IR spectra for the stretching vibrations of $\mathrm{C}-\mathrm{O}$ methyl ester and the rotation vibration of the methyl ester $-\mathrm{CH}_{3}$ for sample no.: a, b-26A; c, d-26B; e, f-26C; $\mathbf{g}, \mathbf{h}-30 \mathrm{~A} ; \mathbf{i}, \mathbf{j}-30 \mathrm{~B} ; \mathbf{k}, \mathbf{l}, \mathbf{m}-30 \mathrm{C}$ 

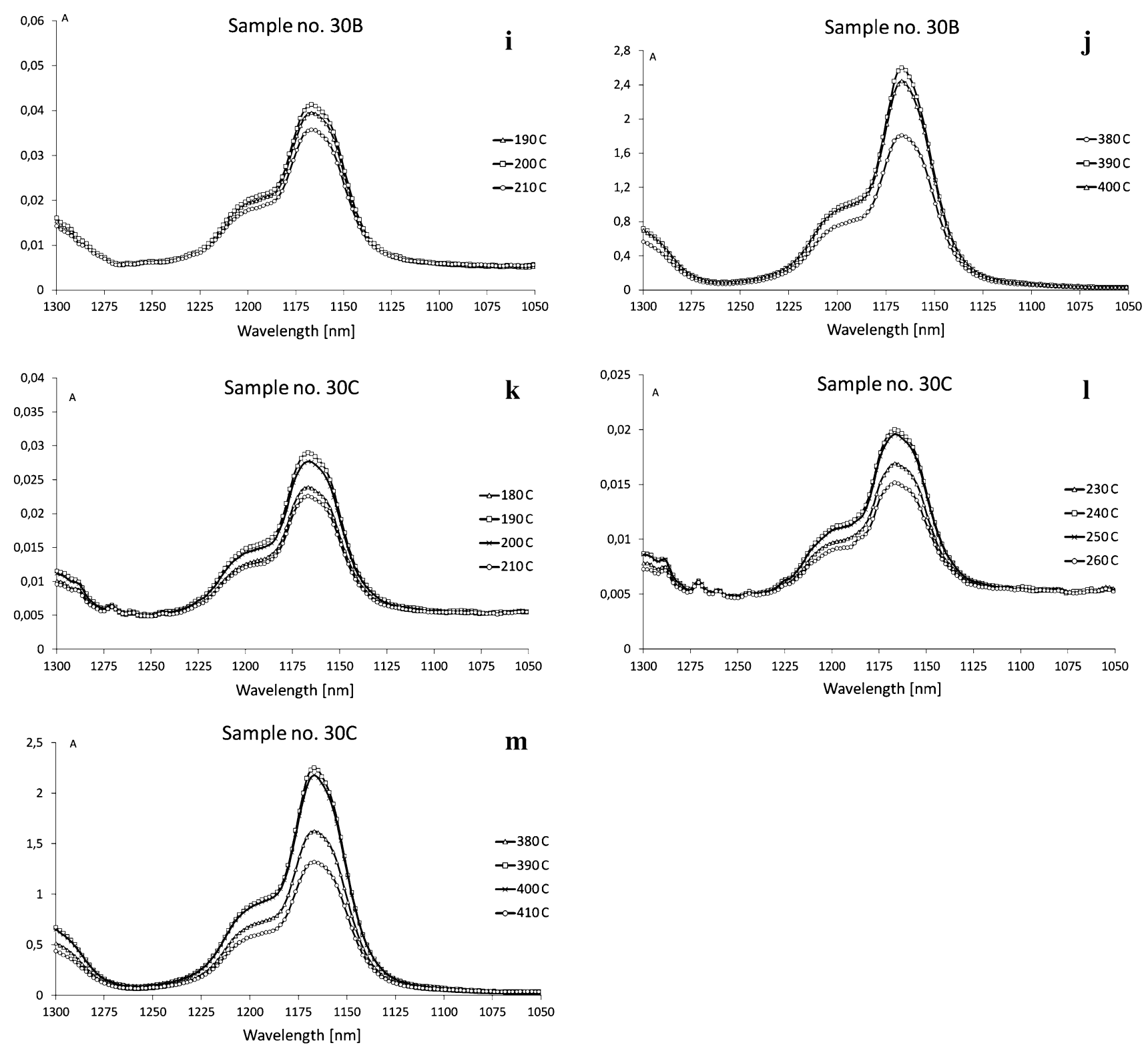

Fig. 3 continued

observed, originating both from the unpolymerized MMA molecules and from PMMA depolymerization. The increase of the band intensity at this wavelength behaves in similar trend, as occurred in the case of stretching vibrations of $\mathrm{C}-\mathrm{O}$ groups and the methyl ester carbonyl group.

The results of mass spectroscopy analysis complement and confirm the results obtained by means of FT-IR spectroscopy. Figure 5 and 6 shows the distribution of ions coming from the MMA (Fig. 5) and ions indicate the presence of fragments derived from MMA containing double bonds in their structure (Fig. 6). In both cases, it can be seen that for the samples containing the lowest concentration of the moderator (no. 30B and no. 30C) ions occur at substantially low temperatures. Therefore it must be concluded that these samples have the worst properties. On the other hand, in the samples where the concentration of the added moderator was 0.7 and $0.8 \mathrm{w} / \mathrm{w} \%$, these ions occur at higher temperatures and these samples exhibit better properties.

Due to the fact that in the technology of optical fibers the important range of temperatures falls from the beginning of the process to a temperature of about $300{ }^{\circ} \mathrm{C}$ only this temperature range was included in the figures.

The internal structure of the polymer preform obtained in the thermal polymerization of the polymer, especially lack of the defects such as the porosity in the linear 

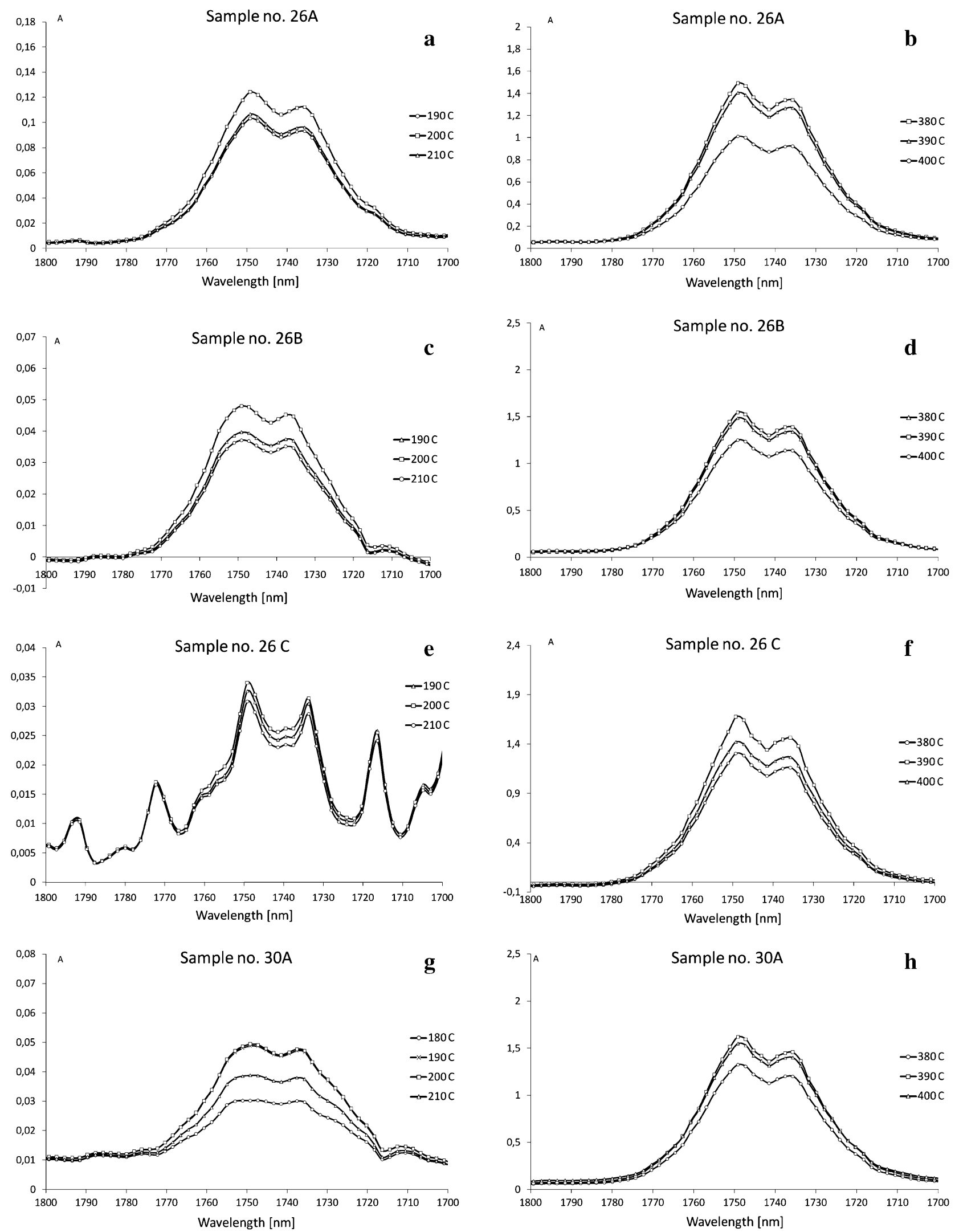

Fig. 4 FT-IR spectra for the stretching vibration of the carbonyl group of the methyl ester for sample no.: a, b-26A; $\mathbf{c}, \mathbf{d}-26 \mathrm{~B}$; e, $\mathbf{f}-26 \mathrm{C}$; $\mathbf{g}, \mathbf{h}-30 \mathrm{~A} ; \mathbf{i}, \mathbf{j}-30 \mathrm{~B} ; \mathbf{k}, \mathbf{l}, \mathbf{m}-30 \mathrm{C}$ 

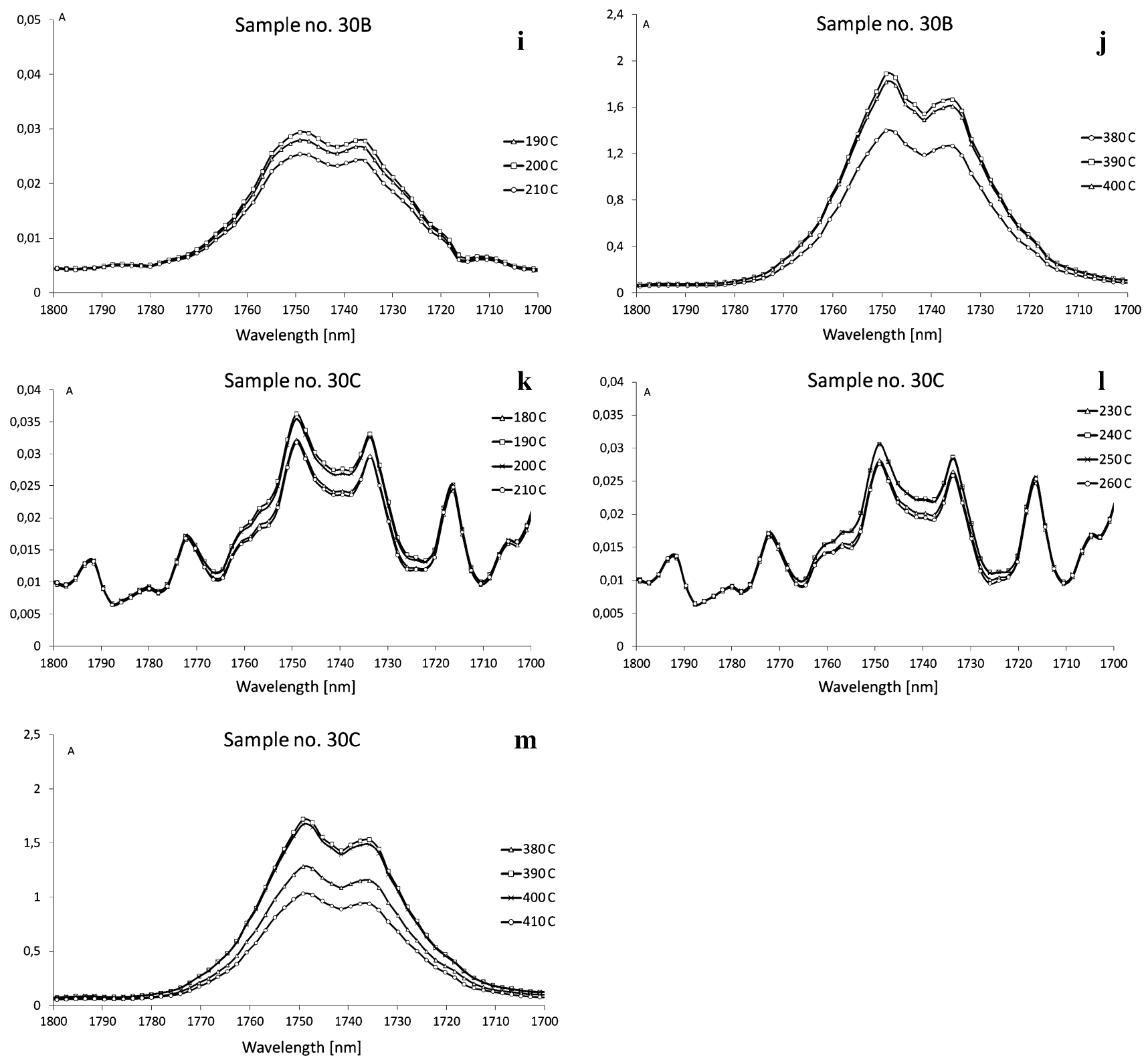

Fig. 4 continued

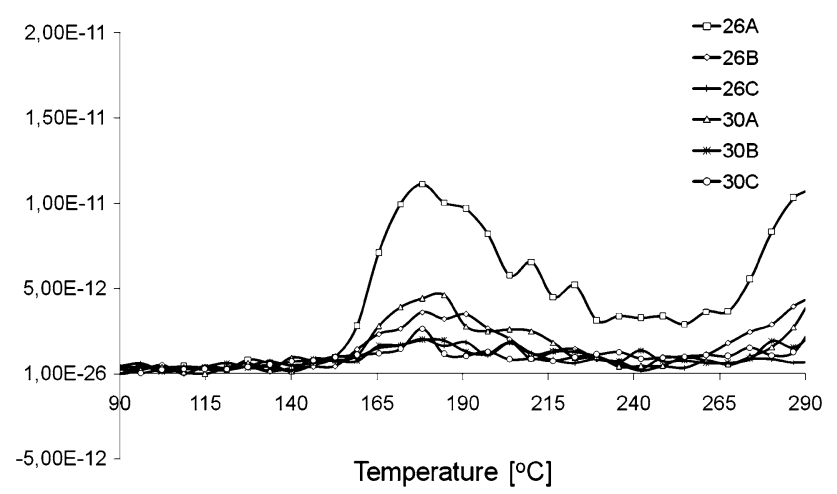

Fig. 5 Temperature distribution of 99 ions coming from MMA

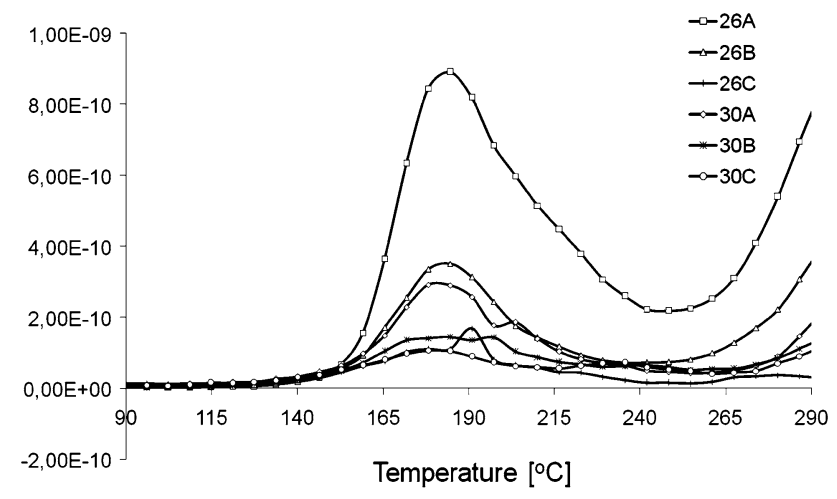

Fig. 6 Temperature distribution of 41 ions indicates the presence of fragments derived from MMA, containing in their structure the double bonds 
Table 5 Parameters characterizing porosity of the investigated samples obtained from nitrogen adsorption/desorption at $77 \mathrm{~K}$ : the surface area, $\mathrm{S}_{\mathrm{BET}}$ and the mean pore diameter $\mathrm{D}_{\mathrm{m}}=4 \mathrm{~V}_{\mathrm{p}} / \mathrm{S}_{\mathrm{BET}}$

\begin{tabular}{lcl}
\hline Sample number & $\mathrm{S}_{\mathrm{BET}}\left(\mathrm{m}^{2} \mathrm{~g}^{-1}\right)$ & $\mathrm{D}_{\mathrm{m}}(\mathrm{nm})$ \\
\hline $26 \mathrm{~A}$ & 8 & 3.0 \\
$26 \mathrm{~B}$ & 6 & 3.3 \\
$26 \mathrm{C}$ & 21 & 1.5 \\
$30 \mathrm{~A}$ & 0 & 0 \\
$30 \mathrm{~B}$ & 4 & 5.5 \\
$30 \mathrm{C}$ & 0 & 5.2 \\
\hline
\end{tabular}

polymer network, is extremely important. Therefore, the low-temperature $\mathrm{N}_{2}$ adsorption/desorption was also measured (Table 5).

As it can be seen, the polymer sample no. 30A obtained at the moderator concentration of $0.6 \mathrm{w} / \mathrm{w} \%$ possesses the smallest surface area and the pore size diameter. Therefore, one can conclude that this sample exhibits the best linear structure. These findings are confirmed by the results of the thermogravimetric analysis and the spectroscopic measurements. Further research will be held to examine on how changing the concentration and type of the added initiator, affects the structure of the resulting polymer. On this basis, it will be possible to optimize the composition of the starting mixtures, and methods of thermal polymerization, in view of the molecular weight of the obtained polymer preform.

\section{Conclusion}

The aim of this work was an investigation of the effect of the moderator concentration on the course of the thermal polymerization. Analyses show that it has an effect on the reaction temperature. The differences in the structure of the resulting polymers can be seen. With the increase in the concentration of the moderator decrease of the adsorption properties can be observed. On the basis of this analysis it was found that samples with a moderator concentration of 0.8 and $0.6 \%$ exhibit better properties than those with the moderator concentration of 0.3 and $0.4 \%$. It has been also confirmed by the thermogravimetric tests, where samples containing the highest concentration of moderator show the lowest mass loss and the highest initial decomposition temperature and also by the fact that only for the highest moderator concentration the optical fiber was drawn.
Acknowledgments This work was supported by Wrocław Research Center EIT + Ltd in the frame of the NanoMat project Application of Nanotechnology in Advanced Materials, within the European Funds for Regional Development, POIG, Sub-action 1.1.2. The authors would like to thank the Laboratory of Applied Chemistry, Faculty of Chemistry, Adam Mickiewicz University in Poznań for the study of textural parameters of the materials.

Open Access This article is distributed under the terms of the Creative Commons Attribution License which permits any use, distribution, and reproduction in any medium, provided the original author(s) and the source are credited.

\section{References}

Borowski, P., Pasieczna-Patkowska, S., Barczak, M., Pilorz, K.: Theoretical determination of the infrared spectra of amorphous polymers. J. Phys. Chem. 116, 7424-7435 (2012)

Brunauer, S., Emmett, P.H., Teller, E.: Adsorption of gases in multimolecular layers. J. Am. Chem. Soc. 60, 309-319 (1938)

Carroll, K., Zhang, C., Webb, D.J., Kalli, K., Argyros, A., Large, M.C.J.: Thermal response of Bragg gratings in PMMA microstructured optical fibers. Opt. Express 15, 8844-8850 (2007)

Dobrosz, K., Matysiak, A.: Tworzywa sztuczne właściwości i zastosowanie. Wydawnictwo Szkolne i Pedagogiczne, Warszawa (1990)

Du, W., Tao, X.M., Tam, H.Y., Choy, C.L.: Fundamentals and applications of optical fiber Bragg grating sensors to textile composites. J. Compos. Struct. 42, 217-230 (1998)

Griffith, A.A.: Phil. Trans. R. Soc. 221A, 160 (1920)

Harlin, A., Myllymaki, H., Grahn, K.: Polymeric optical fibres and future prospects in textile integration. AUTEX Res. J. 2, 132143 (2002)

Im, S.H., Suh, D.J., Park, O.O., Cho, H., Choi, J.S., Park, J.K., Hwang, J.T.: Fabrication of a graded-index polymer optical fiber preform using centrifugal force. Korean J. Chem. Eng. 19(3), 505-509 (2002)

Kersey, A.D.: A review of recent developments in fiber optics sensor technology. Opt. Fiber Technol. 2, 291-317 (1996)

Large, M.C.J., Poladian, L., Barton, G.W., Van Eijkelenborg, M.A.: Microstructured polymer optical fibers. J. Lightwave Technol. 27(11), 1571-1579 (2009)

Liu, H.Y., Peng, G.D., Chu, P.L.: Thermal tuning of polymer optical fiber bragg gratings. IEEE Photonics Technol. Lett. 13, 824-826 (2001)

Liu, H.Y., Liu, H.B., Peng, G.D.: Tensile strain characterization of polymer optical fibre Bragg gratings. Opt. Commun. 251, 37-43 (2005)

Peng, G.D., Chu, P.L.: Polymer optical fiber photosensitivities and highly tunable fiber gratings. Fiber Integr. Opt. Technol. Lett. 11, 352-354 (1999)

Shahzada, A., Sharif, A.: Synthesis and characterization of in situ prepared poly(methyl methacrylate) nanocomposites. Bull. Mater. Sci. 30, 31-35 (2007) 